\title{
Selective 4 Vessels Angiography in Brain Death: A Retrospective Study
}

\author{
Martin Savard, Alexis F. Turgeon, Jean-Luc Gariépy, François Trottier, \\ Stephan Langevin
}

\begin{abstract}
Background: In Canada, ancillary tests, such as selective four vessels angiography (S4VA), are sometimes necessary for brain death (BD) diagnosis when the clinical exam cannot be completed or confounding factors are present. Recent Canadian guidelines assert that brain death is supported by the absence of arterial blood flow at the surface of the brain and that venous return should not be considered. However, neuropathologic and angiographic studies have suggested that arteries might still be patent in BD patients. Current clinical practices in BD diagnosis following S4VA need to be better understood. Methods: We conducted a retrospective study of all S4VA performed for the determination of BD in a level 1 NeuroTrauma centre from 2003 to 2007. The objective of the study was to describe the prevalence of intracranial arterial, capillary (parenchymogram) and venous opacification in our study population. All tests were reviewed independently by two neuroradiologists. Disagreements were resolved by consensus. Results: Thirty two patients were declared BD following S4VA during the study period. Nine of these patients (28\%) presented some proximal opacification of intracranial arteries (95\% CI 15-45\%). As opposed, none had a cerebral capillary and deep venous drainage opacification (95\% CI 010\%). Conclusion: The absence of cerebral deep venous drainage or parenchymogram might represent a better objective marker of cerebral circulatory arrest for brain death diagnosis when the use of S4VA is required. These findings open the path for further research in enhancing our interpretation of angiographic studies for brain death diagnosis.
\end{abstract}

RÉSUMÉ: Étude rétrospective de l'angiographie sélective des 4 vaisseaux pour le diagnostic de la mort cérébrale. Contexte : Au Canada, des tests complémentaires tels l'angiographie sélective des 4 vaisseaux (AS4V) sont parfois nécessaires pour poser le diagnostic de mort cérébrale (MC) quand l'examen clinique est impossible ou lorsque des facteurs confondants sont présents. Selon des lignes directrices canadiennes récentes, la mort cérébrale est confirmée par l'absence de flux sanguin artériel à la surface du cerveau sans tenir compte du retour veineux. Cependant, des études neuropathologiques et angiographiques ont suggéré que les artères pourraient encore être perméables chez les patients en état de MC. Les pratiques cliniques actuelles pour le diagnostic de la MC à l'aide d'une AS4Vdoivent être mieux comprises. Méthodes : Nous avons effectué une étude rétrospective de l'ensemble des AS4V effectulés pour déterminer la MC dans un centre de neuro trauma de niveau 1 de 2003 à 2007. Le but de l'étude était de décrire la prévalence de l'opacification artérielle, capillaire (par parenchymographie) et veineuse intracrânienne dans la population étudiée. Tous les tests ont été révisés indépendamment par deux neuroradiologistes. Les divergences d'opinion ont été résolues par consensus. Résultats : Un diagnostic de $\mathrm{MC}$ a été posé chez trente-deux patients suite à l'AS4V pendant la période de l'étude. Un certain degré d'opacification proximale des artères intracrâniennes était présente chez neuf de ces patients (28\% ; IC à 95\%: 15\% à 45\%). Par contre, aucun n'avait une opacification des capillaires cérébraux et du drainage veineux profond (IC à 95\%: $0 \%$ à 10\%). Conclusion : L'absence de drainage veineux cérébral profond ou de parenchymographie pourraient constituer un meilleur marqueur objectif de l'arrêt de la circulation cérébrale pour le diagnostic de MC quand on doit recourir à l'AS4V. Ces observations ouvrent la voie à des recherches plus poussées sur l'interprétation des études angiographiques dans le diagnostic de la MC.

Can. J. Neurol. Sci. 2010; 37: 492-497

In Canada, neurologic determination of death (NDD) or brain death (BD) diagnosis is based on five clinicals criteria: established etiology capable of causing NDD, deep unresponsive coma, absent brainstem reflexes, absent breathing reflex and absent confounding factors. ${ }^{1}$ However, ancillary tests are sometimes necessary when the clinical exam cannot be completely performed or when confounding factors are present. Recently, a Canadian workforce of experts in brain death and organ donation published guidelines on the use of ancillary tests for NDD. ${ }^{2}$ Among their recommendations, they stated that "Absence of brain blood flow is the imaging and physiological correlate of brain arrest and brain death. From an imaging point of view, brain blood flow refers to intra-arterial filling and the visualisation of large vessels in the hemispheres and the posterior fossa". In the Key considerations the Canadian expert report mentioned "(...) brain blood flow should be absent in the

From the Département des Sciences Neurologiques (MS), Département d'Anesthésiologie, Service de Soins Intensifs (AFT, SL), Unité de Recherche en Traumatologie - Urgence - Soins Intensifs, Centre de Recherche du CHA (AFT), Département de Radiologie (JLG, FT), Centre Hospitalier Affilié Universitaire de Québec, Hôpital de l'Enfant-Jésus, Université Laval, Québec, Québec, Canada. Received November 5, 2009. Final Revisions Submitted February 16, 2010. Correspondence to: Martin Savard, Département des Sciences Neurologiques, Centre Hospitalier Affilié Universitaire de Québec, Hôpital de l'Enfant-Jésus, 1401 18e rue, Québec, Québec, G1J 1Z4, Canada. 
large vessels of the cerebral hemispheres and posterior fossa structures" but that "blood flow to the portion of the intracranial space that lies exterior to the surface of the brain, but interior to the cranium, may still be detectable. This does not contradict the diagnosis (of NDD). (...) There is no need to consider the venous phase in this clinical setting." By contrast, the 2007 guidelines of the French Society of Neuroradiology on the use of computed tomographic angiography (CTa), a country where ancillary tests are mandatory to declare BD, stated that NDD should be based on the absence of opacification of deep venous drainage of the brain and no bilateral opacification of cortical branch of the middle cerebral artery (M4, MCA) at 60 seconds. ${ }^{3}$

Interestingly, it was observed in cadavers a few decades ago that arteries could still be patent in BD patients. ${ }^{4}$ Moreover, the performance of selective four vessels angiography (S4VA) requires intra-arterial contrast injected under pressure, which could exceed the intracranial pressure..$^{5}$ Thus, the presence of some contrast media in proximal intracranial arteries could still be compatible with NDD diagnosis, as proposed by data from angiographic studies ${ }^{5-11}$ Furthermore, the absence of contrast in the capillary circulation (parenchymogram) and in the intracranial deep venous drainage system at the S4VA seems sufficient to support intracranial circulatory arrest, compatible with BD.

In order to better describe the prevalence of intracranial arterial filing in BD patients, we conducted a retrospective study of all S4VA performed in our centre in presumed BD patients over a period of five years. We hypothesized that some patients may show angiographic evidence of intracranial arterial opacification, but none during the intracranial capillary and deep venous drainage.

\section{Methods}

All S4VA performed as an ancillary test for NDD in a single level 1 NeuroTrauma centre (Hôpital de l'Enfant-Jésus, Quebec City, Quebec, Canada), between January 1st 2003 and December 31st 2007 were reviewed. Patients were identified through an organ donation database, which contains information collected by one of three nurses dedicated to the hospital donation program. Patient identification was then cross-validated with the database from Québec-Transplant, the organisation managing organ donation and transplants programs in the province of Quebec, Canada. This study was approved by the hospital Research Ethic Board.

\section{Rational for S4VA and BD diagnosis}

During the study period, all S4VA were requested by the attending intensivist as brain death ancillary tests when considered necessary in patients with suspected but unconfirmed BD. A diagnosis of BD was suspected with the presence of: 1) an established etiology capable of causing BD, 2) a deep unresponsive coma, 3) an absence of all brainstem reflexes that can be evaluated, 4) a positive apnea test, and 5) an absence of confounding factor. The criteria for performing S4VA studies were mainly the followings: 1) incapacity to perform a complete neurological examination, or 2) presence of a confounding factor precluding NDD diagnosis. Brain death was confirmed when intracranial arterial opacification was absent. When opacification of intracranial arteries was present, the absence of intracranial capillary and of deep venous drainage opacifications were mandatory in order to confirm BD.

\section{Data collection}

Demographic and clinical data were collected by one of the investigators (SL) both from the hospital organ donation database and from patient charts. Intracranial pressure (ICP) and blood pressure were defined as the highest values recorded once fixed bilateral mydriasis was observed (or unilateral when only one eye could be assessed). Suspicion of BD diagnosis was defined as the time when cranial nerve reflexes were absent, associated with either a positive apnea test or absence of the cough reflex. High blood pressure associated with transtentorial herniation was defined as any event of high blood pressure over 160/90 $\mathrm{mm} \mathrm{Hg}$ following fixed mydriasis in adults (i.e. in patients over 16-years-old) and two standard deviations over the normal blood pressure in younger patient. $^{12}$ A significant comminuted skull fracture was defined as any cranial comminuted fracture seen at the CT scan, with the limitation that we could not be sure that there was a dura mater defect. The cause of death and reasons why an ancillary test was required were also collected. All clinical data were collected prior to the performance of the S4VA.

\section{S4VA technique}

All S4VA studies were performed by one of three neuroradiologists with selective injection of contrast media in both carotids and vertebral arteries through catheterisation of the right femoral artery. Injections used $8 \mathrm{~mL}$ of iodine contrast
Table 1: Anatomic classification of cerebral angiography

Basilary trunk (BT)

Anterior cerebral artery (A1-3)

Middle cerebral artery (M1-4)

Posterior cerebral artery (P1-4)

Anterior communicant (AC)

Posterior communicant (PC) 
Table 2: Characteristics of the study population

\begin{tabular}{|c|c|c|}
\hline & $\begin{array}{l}\text { Patient without arterial } \\
\text { intracranial opacification }\end{array}$ & $\begin{array}{l}\text { Patient with arterial } \\
\text { intracranial opacification }\end{array}$ \\
\hline Female gender & $11 / 23$ & $3 / 9$ \\
\hline Median age (range) & $17(3-61)$ & $42(5-64)$ \\
\hline Comminuted skull fractures & $3 / 23$ & $3 / 9$ \\
\hline Craniectomy with no flap replacement & $1 / 23$ & $1 / 9$ \\
\hline Ventriculostomy & $14 / 23$ & $1 / 9$ \\
\hline Use of ICP monitoring & $14 / 23$ & $1 / 9$ \\
\hline - Median highest ICP (range) & $92(35-150) \mathrm{mm} \mathrm{Hg}$ & 102 mm Hg (1 patient) \\
\hline $\begin{array}{l}\text { Presence of diabetes insipidus (vasopressin use } \\
\text { among patient without diabetes insipidus) }\end{array}$ & $18 / 23(4 / 5)$ & $8 / 9(1 / 1)$ \\
\hline Documented HBPAH & $9 / 23$ & $5 / 9$ \\
\hline Use of vasopressors after BD diagnosis & $23 / 23$ & $8 / 9$ \\
\hline
\end{tabular}

ICP: intracranial pressure; HBPAH: high blood pressure associated with transtentorial herniation; BD: brain death

media (Visipaque 270) at $4 \mathrm{~mL} / \mathrm{sec}$ in each of the four vessels, using a 5-French catheter. Cervical and intracranial images were acquired in order to assess intracranial arterial, capillary (parenchyma) and deep venous drainage vascular system over a minimum of a 20 -second period. The angiographic classification used to evaluate the arterial system is described in Table 1. Intracranial opacification was defined as any contrast seen above the C5 and/or V4 levels. An intracranial capillary opacification was defined as the presence of contrast media in nervous tissue between the arterial and venous drainage phase. A deep venous drainage opacification was considered when any profound vein (septal, anterior caudate, terminal, thalamostriate, internal cerebral, Galen, inferior ventricular, Rosenthal, inferior sagittal sinus, straight sinus, medial atrial, medullary) showed contrast media.

\section{Independent radiological evaluation}

All S4VA studies were reviewed and interpreted independently by two neuroradiologists (JLG and FT) using a standardized case report form. Disagreement was defined as a difference of one level according to a standardized classification of the intracranial arteries (see Table 1), or any different opinion concerning the presence of intracranial capillary (parenchymal) or deep venous drainage opacification. Disagreements were then resolved by consensus.

\section{Statistical Analyses}

Data are presented in a descriptive manner. Inter-rater reliability between the two observers was evaluated for each one of the four vessels (left and right carotids and vertebral arteries) using Kappa statistics. A Weighted Kappa $>0.40$ was considered a moderate agreement, when a Weighted Kappa $>0.60$ was considered a good agreement. ${ }^{13}$

\section{RESULTS}

Over the study period, 141 patients had a diagnosis of BD. Thirty two of them (23\%) required an ancillary test for NDD, which was S4VA in all cases, performed on average less than four hours following suspicion of BD diagnosis. Patients were aged between 3 and 64 years old (see Table 2). The main cause

Table 3: Causes of death among patient population

\begin{tabular}{lll}
\hline Causes of death & $\begin{array}{l}\text { Patients without arterial } \\
\text { intracranial opacification }\end{array}$ & $\begin{array}{l}\text { Patients with arterial } \\
\text { intracranial opacification }\end{array}$ \\
\hline Traumatic brain injury & $19 / 23$ & $6 / 9$ \\
Subarachnoid hemorrhage & $3 / 23$ & $1 / 9$ \\
Anoxic-ischemic injury & $0 / 23$ & $2 / 9$ \\
Spontaneous cerebral bleeding & $1 / 23$ & $0 / 9$ \\
\hline
\end{tabular}


Table 4: Reasons to perform S4VA

\begin{tabular}{lll}
\hline Reasons to use an ancillary test & $\begin{array}{l}\text { Patients without arterial } \\
\text { intracranial opacification }\end{array}$ & $\begin{array}{l}\text { Patients with arterial } \\
\text { intracranial opacification }\end{array}$ \\
\hline Inadequate clinical exam* & $11 / 23$ & $5 / 9$ \\
Barbituric coma & $9 / 23$ & $1 / 9$ \\
Sedation (other than barbiturics) & $2 / 23$ & $1 / 9$ \\
Hypoxemia & $2 / 23$ & $0 / 9$ \\
Hemodynamic instability & $0 / 23$ & $1 / 9$ \\
Eye opening to peripheral pain & $1 / 23$ & $0 / 9$ \\
Suspected intoxication & $0 / 23$ & $1 / 9$ \\
\hline
\end{tabular}

* include unsatisfactory apnea test; Note: Reasons are not mutually exclusive; 2 patients had 2 reasons justifying the use of S4VA.

of death was traumatic brain injury (see Table 3). The most frequent clinical justification for ancillary test was an incomplete cranial nerves evaluation for BD diagnosis (inadequate clinical exam) and the use of barbiturates in the setting of intracranial pressure control (see Table 4).

The median number of images obtained per angiographic study was 37 (range 24-54). Inter-observer agreement concerning the absence of intracranial capillary and the deep venous drainage between the two neuroradiologists was $100 \%$. A good agreement was observed in the evaluation of the arterial opacification of left and right carotids, and of left vertebral arteries (Weighted Kappa $=0.76,0.72$ and 0.71, respectively), while a moderate agreement was observed for the right vertebral arteries (Weighted Kappa $=0.40$ ). However, a consensus was obtained for each cases.

None of these 32 patients had visible opacification of intracranial capillary or deep intracranial veins. Likewise, there was no opacification of the superior sagittal sinus. However, 9 of these 32 patients had some intracranial arterial opacification (see Table 5; Figures 1 and 2). Among patients with intracranial arterial opacification, the clinical justification for performing a S4VA in five of these was an incomplete cranial nerves evaluation for BD diagnosis and/or unsatisfactory apnea test (see Table 4). The presence of confounding factors was the main justification for the remaining patients. Finally, we observed a higher incidence of comminuted skull fractures among patients with intracranial arterial opacification (see Table 2). No decompressive craniectomy were performed in any of the patients.

The absence of contrast in both intracranial capillaries and deep veins, added to the clinical exam, convinced both clinicians and neuroradiologists that these nine patients met BD diagnosis criteria, which is consistent with the French experience with CTa as related before. This was also supported by the presence of surrogate markers of brain death including diabetes insipidus and the clinical need for vasopressors (see Table 2). In accordance with the findings, all 32 patients included in this study were considered for organ donation. As per provincial law, a second evaluation for BD diagnosis was performed by a certified neurologist. The original BD diagnosis was supported in all 32 patients.

\section{Discussion}

This retrospective study of 32 cases of BD showed that when S4VA was used as an ancillary test for NDD, intracranial arterial opacification was a common finding occurring in close to $30 \%$ of the study population. However, opacification of intracranial capillaries and deep veins was never observed in any of these patients, thus this specific observation is likely compatible with intracranial circulatory arrest. Consequently, despite these findings, these patients were declared brain dead by a group of experienced physicians including intensivists, neurologists and neuroradiologists.

Our findings are consistent with previously published studies where opacification of intracranial arteries was observed in patients with proven BD from clinical exam. ${ }^{5,9,11}$ In none of these studies patients had venous filling, except for some with longitudinal sagittal sinus or lateral sinus contrast, usually reported to occur with the presence of shunt through emissary

Table 5: Area perfused on S4VA

\begin{tabular}{lll}
\hline Arteries & N=9 & Perfused area \\
\hline Distal trunk of left internal carotid & 4 & $\mathrm{C} 7: 2 ; \mathrm{A} 1 \mathrm{M} 1: 1 ; \mathrm{A} 2 \mathrm{M} 2: 1$ \\
Distal trunk of right internal carotid & 5 & $\mathrm{C} 7: 4 ; \mathrm{A} 1 \mathrm{M} 2: 1$ \\
Distal trunk of left vertebral & 2 & $\mathrm{P} 1: 1 ; \mathrm{P} 1 \mathrm{PC}: 1$ \\
Distal trunk of right vertebral & 2 & $\mathrm{P} 3 \mathrm{M} 3: 1 ; \mathrm{P} 3 \mathrm{P} 4: 1$ \\
\hline
\end{tabular}




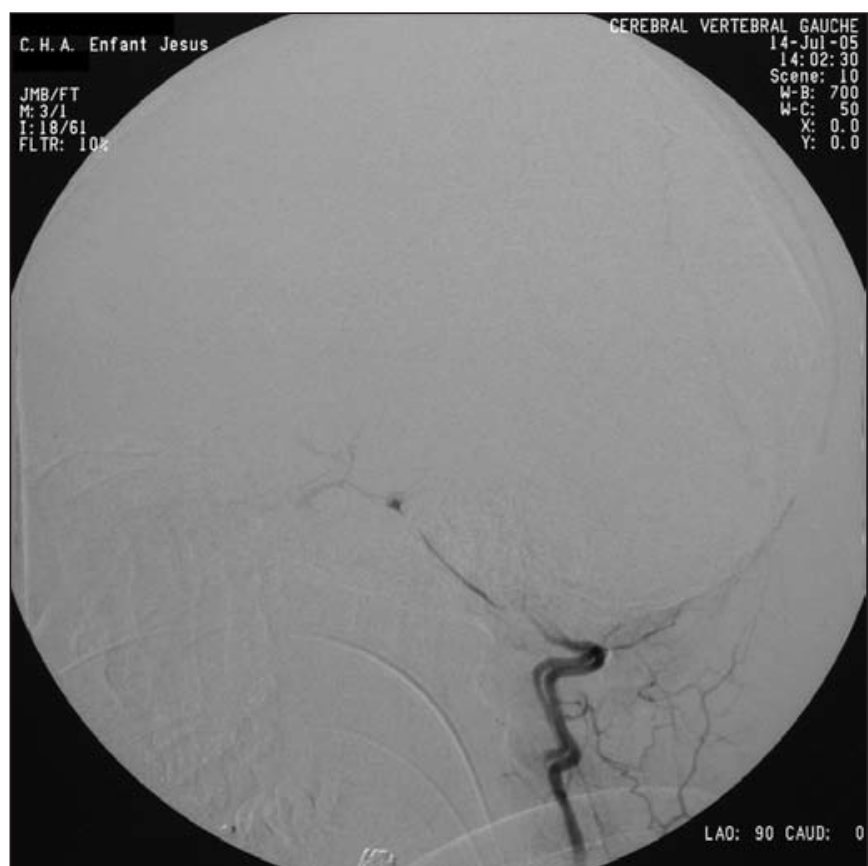

Figure 1: Left vertebral artery angiogram, lateral view in capillary phase, showing opacification of the basilar artery with no parenchymogram or venous opacification in later phase.

vein from the external carotid circulation..$^{5,10}$ However, in one study performed in $140 \mathrm{BD}$ patients using intravenous angiography, nine of them (6\%) demonstrated the delayed presence of some contrast in the posterior fossa venous system; supracavernous arterial contrast was observed in $37 \%$ of vessels studied while vertebrobasilar arterial contrast was observed in $17 \%$ of patients. ${ }^{10}$

A possible explanation for intracranial arterial opacification could be the progressive increase of intracranial pressure and its effect on the intracranial circulatory system. As ICP rises to uncontrolled values, intracranial vessels are compressed in a sequential manner. We can hypothesize that capillaries and small veins are compressed first, followed by other vessels depending of their size and compliance. When intracranial capillaries and small veins are compressed, intracranial circulatory arrest occurs. At this time, the intracranial arteries and parts of intracranial sinuses are still patent. ${ }^{4}$ The absence of opacification of intracranial arteries might then occur as a late phenomenon by progressive collapse and/or thrombosis. The circulatory arrest theory is also supported by studies using transcranial dopplers to evaluate intracranial vascular flow. ${ }^{14-17}$ With this modality, specific intracranial flow patterns associated with no forward blood flow but necessarily with the presence of mobile red blood cells in the brain (the "to and fro" and the narrow systolic spike flow) were found to be $89 \%$ sensitive and $99 \%$ specific to help confirm BD in a recent meta-analysis of ten studies. ${ }^{18}$ These observations are also supported by studies using CTa in clinically proven BD patients where absence of venous opacification showed a higher sensitivity (86-100\%) to support NDD as compared to absence of arterial opacification $(52-77 \%) .{ }^{19-22}$

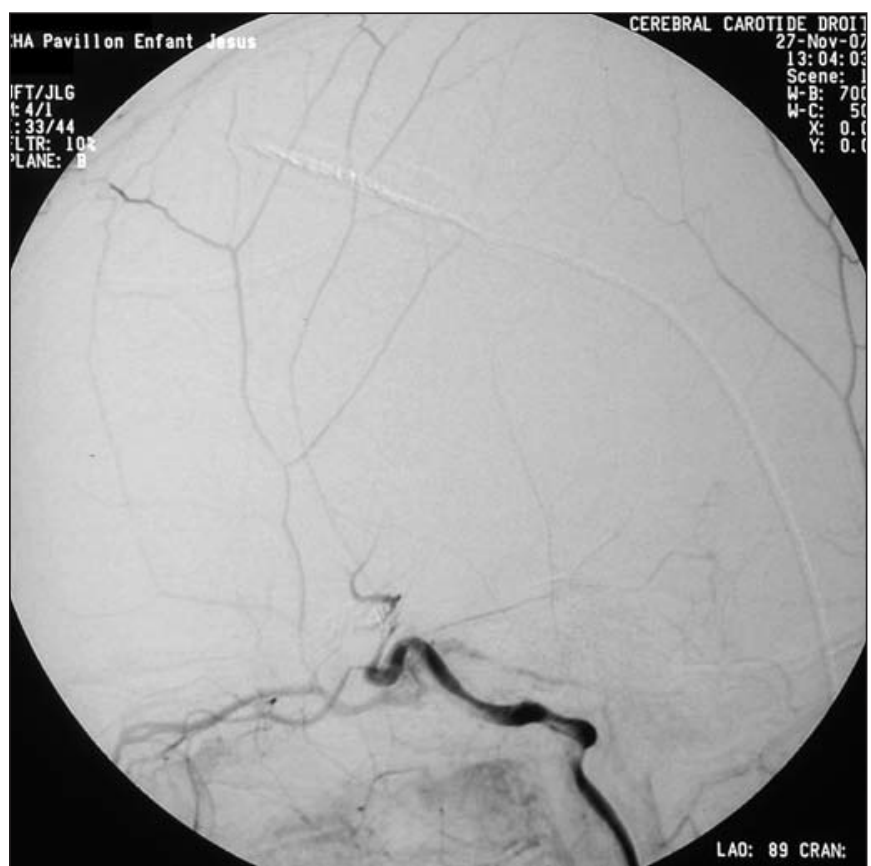

Figure 2: Right internal carotid artery, lateral view in late arterial phase, showing opacification of supraclinoid internal carotid artery and sylvian artery, without parenchymogram or venous opacification in later phase.

Furthermore, it was suggested that only considering the venous phase in either CTa or S4VA could minimize the delay for the diagnosis of BD. ${ }^{22}$

The angiographic technique could also provide another explanation for the commonly encountered proximal arterial filling when, in certain situations, a high number of angiographic images are required to adequately evaluate the intracranial perfusion over a variable period of time following contrast media injection. The duration of the technique might then be in relation with the observation of late arterial filling. Two recent studies supported this argument. ${ }^{9,10}$ In one study where images were acquired 20 seconds following contrast injection, the authors reported a $2.5 \%$ (1/40) incidence of proximal artery opacification with S4VA as opposed to $24 \%$ (34/120) when these images were acquired 60 seconds after injection..$^{9,10}$ In addition, the injection pressure could also be a factor involved since a high injection pressure might overcome the intracranial pressure leading to a certain degree of intracranial arterial opacification, as described previously. ${ }^{5}$ Finally, the timing of the S4VA study following the presumed clinical diagnosis of $\mathrm{BD}$ might be a factor explaining why intracranial arterial opacification might be present.

This study has limitations. First, its retrospective design precluded obtaining additional angiographic images to clarify perfusion in some specific intracranial areas, such as in the presence of extracranial herniation of cerebrum that could account for some blood flow within the herniated tissue. Second, despite the fact that only three neuroradiologists performed the S4VA technique, the latter was not perfectly standardized for the quantity of contrast media injected and time of the acquisition of images. Third, the two neuroradiologists reviewing the S4VA 
knew that all included patients became organ donors and were involved in performing most of these S4VA procedures. In addition, the level of agreement between the two neuroradiologists was good for most vessels, but moderate for one, regarding the arterial evaluation phase for their initial independent evaluation. We hypothesize that irregularities and thread-like picture (see Figures 1 and 2) are more often observed with arterial vessels leading to a certain degree of inter-observer variability. Moreover, the use of a more detailed anatomic definition of the different arterial segments compared to the dichotomous capillary and venous phase definitions could also explain part of the difference observed between our experts. However, because an agreement was reached after discussion, it might reflect the difficulty pertaining to the interpretation of the arterial phase and the need for better standardized definitions. On the other hand, only one patient in the group with arterial opacification had an intracranial pressure (ICP) monitoring thus precluding to clearly correlate our findings with an objective intractable increased ICP. Moreover, the higher incidence of comminuted skull fractures was higher in patients with arterial opacification which could have lead to a certain level of decompression in this group of patients. However, it was not known if the dura mater was disrupted or not and thus if there was decompression or not with these fractures. More importantly, whether this impact is clinically significant in patients with persistent increased ICP remains unknown. ${ }^{23}$ Finally, since all S4VA studies were performed in patients with factors precluding clinical BD diagnosis, we cannot compare our results with the gold standard diagnostic test. The systematic presence of surrogate markers of $\mathrm{BD}$, however, helps confirm their BD status.

\section{Conclusion}

In this retrospective cohort study, we observed that some patients were declared BD following S4VA by experienced neuroradiologists despite the presence of some proximal intracranial arterial opacification. Considering that all patients had a clinical presentation suggestive of $\mathrm{BD}$, however not confirmed by a complete clinical examination, it might suggest that the presence of proximal intracranial arterial opacification, when associated with absence of contrast media in the capillary and venous circulation, may not be clinically significant to preclude the diagnosis of intracranial circulatory arrest and $\mathrm{BD}$ in most patients. Considering the impact and importance of $\mathrm{BD}$ declaration, along with the necessary use of ancillary tests in many situations, we think that the definition of positive BD criteria using S4VA should be clearer than the one proposed in the current Canadian Guidelines. Thus, a prospective study evaluating angiographic imaging modalities in clinically proven $\mathrm{BD}$ patients using a standardized protocol is warranted to evaluate the presence and clinical significance of proximal intracranial arterial opacification, especially with the emergence of new technologies.

\section{AKNOWLEDGEMENTS}

The authors thank Dr. Robert Laforce Jr. for his help in the final redaction of this manuscript. Dr. Turgeon is a recipient of a Clinical Research Career Award from the Fonds de la Recherche en Santé du Québec (FRSQ) and is supported by an operational grant from the FRSQ (\#015102).

\section{REFERENCES}

1. Shemie SD, Doig C, Dickens B, Byrne P, Wheelock B, Rocker G, et al. Severe brain injury to neurological determination of death: Canadian forum recommendations. CMAJ. 2006; 174(6): S1-13.

2. Shemie SD, Lee D, Sharpe M, Tampieri D, Young B. Brain blood flow in the neurological determination of death: Canadian expert report. Can J Neurol Sci. 2008; 35: 140-6.

3. Leclerc X. CT angiography for the diagnosis of brain death: recommendations of the French society of neuroradiology. J Neuroradiol. 2007; 34: 217-9.

4. Langfitt TW, Kassel NF. Non-filling of cerebral vessels during angiography: correlation with intracranial pressure. Acta Neurochir (Wien). 1966; 14: 96-104.

5. Vlahovitch $B$, Frèrebeau $\mathrm{P}$, Kuhner $\mathrm{A}$, Billet $\mathrm{M}$, Gros $\mathrm{C}$. Les angiographies sous pression dans la mort du cerveau après arrêt circulatoire encéphalique. Neurochirurgie. 1971; 17(2): 81-96.

6. Van Bunnen Y, Delcour C, Wery D, Richoz B, Struyven J. Intravenous digital substraction angiography. A criteria of brain death. Ann Radiol. 1989; 32(4): 279-81.

7. Kricheff II, Pinto RS, George AE, Braunstein P, Korein J. Angiographic findings in brain death. Ann N Y Acad Sci. 1978; 315: 168-83.

8. Bradac GB, Simon RS. Angiography in brain death. Neuroradiology. 1974; 7(1): 25-8.

9. Munari M, Zuccheta P, Carollo C, Gallo F, De Nardin M, Marzola $\mathrm{MC}$, et al. Confirmatory tests in the diagnosis of brain death: comparison between SPECT and contrast angiography. Crit Care Med. 2005; 33(9): 2068-73.

10. Braun M, Ducrocq X, Huot JC, Audibert G, Anxionnat R, Picard L. Intravenous angiography in brain death: report of 140 patients. Neuroradiology. 1997; 39(6): 400-5.

11. Korein J, Braunstein P, George A, Wichter M, Kricheff I, Lieberman A, et al. Brain Death: I. Angiographic correlation with the radioisotopic bolus technique for evaluation of critical deficit of cerebral blood flow. Ann Neurol. 1977; 2: 195-205.

12. Park MK, Menard SW, Schoolfield J. Oscillometric blood pressure standards for children. Pediatr Cardiol. 2005; 26(5): 601-7.

13. Altman DG. Practical statistics for medical research. London England: Chapman and Hall; 1991.

14. de Freitas GR, André C, Bezerra M, Nunes RG, Vincent M. Persistence of isolated flow in the internal carotid artery in brain death. J Neurol Sci. 2003; 210(1-2): 31-4.

15. Petty GW, Mohr JP, Pedley TA, Tatemichi TK, Lennihan L, Duterte DI, et al. The role of transcranial doppler in confirming brain death: sensitivity, specificity, and suggestion for performance and interpretation. Neurology. 1990; 40(2): 300-3.

16. Powers AD, Graeber MC, Smith RR. Transcranial doppler ultrasonography in the determination of brain death. Neurosurgery. 1989; 24(6): 884-9.

17. Ducrocq X, Braun M, Debouverie M, Junges C, Hummer M, Vespignani H. Brain death and transcranial doppler: experience in 130 cases of brain dead patients. J Neurol Sci. 1998; 160(1): 41-6.

18. Monteiro LM, Bollen CW, van Huffelen AC, Ackerstaff RG, Jansen NJ, van Vught AJ. Transcranial doppler ultrasonography to confirm brain death: a meta-analysis. Intensive Care Med. 2006; 32(12): 1937-44.

19. Leclerc X, Taschner CA, Vidal A, Strecker G, Savage J, Gauvrit JY, et al. The role of spiral CT for the assessment of the intracranial circulation in suspected brain-death. J Neuroradiol. 2006; 33: 90-5.

20. Dupas B, Gayet-Delacroix M, Villers D, Antonioli D, Veccherini MF, Soulillou JP. Diagnosis of brain death using two-phase spiral CT. Am J Neuroradiol. 1998; 19: 641-7.

21. Quesnel C, Fulgencio JP, Adrie C, Marro B, Payen L, Lembert N, et al. Limitation of computed tomographic angiography in the diagnosis of brain death. Intensive Care Med. 2007; 33: 2129-35.

22. Combes JC, Chomel A, Ricolfi F, d'Athis P, Freysz M. Reliability of computed tomographic angiography in the diagnosis of brain death. Transplant Proc. 2007; 39: 16-20.

23. Daboussi A, Minville V, Leclerc-Foucras S, Geeraerts T, Esquerré JP, Payoux P, et al. Cerebral hemodynamic changes in severe head injury patients undergoing decompressive craniectomy. J Neurosurg Anestheriol. 2009, 21: 339-45. 